\title{
APPLICATION OF PLASTICIZED CELLULOSE TRIACETATE MEMBRANES FOR RECOVERY AND SEPARATION OF CERIUM(III) AND LANTHANUM(III)
}

\author{
Beata Pospiech*, Adam Makowka \\ Department of Materials Engineering, Czestochowa University of Technology, Armii Krajowej 19, 42-200 Czestochowa, Poland \\ *Corresponding author. E-mail: beata.pospiech@pcz.pl
}

\begin{abstract}
:
This work explains the application of plasticized cellulose triacetate (CTA) membranes with Cyanex 272 di(2,4,4(trimethylpentyl)phosphinic acid) and Cyanex 301 (di(2,4,4-trimethylpentyl)dithiophosphinic acid) as the ion carriers of lanthanum(III) and cerium(III). CTA is used as a support for the preparation of polymer inclusion membrane (PIM). This membrane separates the aqueous source phase containing metal ions and the receiving phase. $1 \mathrm{M} \mathrm{H}_{2} \mathrm{SO}_{4}$ is applied as the receiving phase in this process. The separation properties of the plasticized membranes with Cyanex 272 and Cyanex 301 are compared. The results show that the transport of cerium(III) through PIM with Cyanex 272 is more efficient and selective than lanthanum(III).
\end{abstract}

\section{Keywords:}

Polymer inclusion membrane (PIM), Cyanex 272, Cyanex 301, lanthanum(III), cerium(III)

\section{Introduction}

The separation of metal ions is an important step in the process of obtaining valuable materials. The classic methods of separation include: solvent extraction, ion exchange, crystallization, membrane methods, etc. Application of polymer inclusion membranes (PIMs) can be a useful method for concentration of aqueous solution containing metal ions as well as for their selective recovery [1-3]. Nowadays, PIMs are applied only on a small, laboratory scale since there is no industrial installation that is available for the application of PIMs. However, PIM technology can be more competitive with conventional, costly processes. Above all, synthesis of this membrane requires a small amount of organic solvents and extractants. Furthermore, its advantage is that the extraction of metal ions and the reextraction can be done continuously. The same membrane can be used several times in a separation process under various conditions. Moreover, this method can be used for the separation of different species (antibiotics, inorganic anions, small molecules, and so on).

The components of the PIM play an important role in separation process. The PIMs are prepared by dissolving a polymer (i.e., cellulose triacetate [CTA]), an ion carrier, and a plasticizer in an organic solvent, and followed by the slow evaporation of the solvent. Polymer provides the membrane with the required mechanical strength and forms a flexible, stable, and thin film. The ion carrier determines the selectivity of the process. The plasticizer is added into the PIM to make the membrane more flexible. Moreover, this component performs the function of the solvent for the carrier. The membrane containing the appropriate ion carrier is used to separate two aqueous phases: the source phase containing mixture of metal ions and the receiving phase (e.g., inorganic acid) [4-8]. The efficiency and selectivity of the metal ions transferred through membrane mainly depend on the kind of carriers. The organophosphorus acids, amine-based compounds (quaternary ammonium and phosphonium salts and tertiary amines), and neutral or solvating extractants are used as the carriers for synthesis of PIM [1, 2, 9-12]. The most important advantages of PIMs' application are their low cost of process and high selectivity [1-6]. On the other hand, the drawbacks of PIMs are their relatively low diffusion coefficient and long-lasting transport across membrane [1]. However, separation of metal ions through PIM can be more attractive compared to solvent extraction with higher organic substances consumption and two step operation (extraction and stripping) [6].

Recovery and separation of rare earth elements (REEs) from aqueous solutions is a difficult, but very important, stage in hydrometallurgical processing of electronic wastes. REEs, in particular lanthanum (La) and cerium (Ce), are necessary for production of catalysts, batteries (i.e., $\mathrm{NiMH}$ ), optical glasses, etc. [13-18]. Leach liquors from hydrometallurgical processes contain many useful metals, which should be separated before recovery as pure metals. The separation of REEs from aqueous solutions is a huge challenge due to their similar physicochemical properties. The solvent extraction was very often used for separation of metal ions. Many commercial organophosphorous extractants were applied as the extractant of metal ions (i.e., Cyanex 301 - bis(2,4,4-trimethylpentyl) dithiophosphinic acid, Cyanex 272 - bis(2,4,4-trimethylpentyl) 
phosphinic acid, D2EHPA (bis-2-ethylhexyl phosphoric acid) and PC-88A (2-ethylhexyl phosphonic acid mono-2-ethylhexyl ester), etc.) [19-27]. However, this process was not selective enough, especially for $\mathrm{Ce}(\mathrm{III})$ and $\mathrm{La}(\mathrm{III})$. For example, the extraction efficiencies of $\mathrm{La}(\mathrm{III})$ and $\mathrm{Ce}$ (III) using $0.5 \mathrm{M}$ D2EHPA in kerosene were $83.5 \%$ and $95.6 \%$, respectively, and the separation coefficient $\left(\mathrm{S}_{\mathrm{Ce} / \mathrm{La}}\right)$ was only 4.9 [16]. The other authors also indicated limitations of this separation method because of the poor extraction selectivity of REE ions [17-20].

Transport across PIM can be considered as the alternative method of metal ions' separation from aqueous solutions. Organophosphorous acids such as: D2EHPA, Cyanex 272, and Cyanex 301 were used as the effective ion carriers of $\mathrm{Zn}(\mathrm{II})$, $\mathrm{Cd}(\mathrm{II})$, and $\mathrm{Pb}(\mathrm{II})$ by Kozlowska et al. [12]. The preferential selectivity order was the following: $\mathrm{Pb}(\mathrm{II})>\mathrm{Cd}(\mathrm{II})>\mathrm{Zn}(\mathrm{II})$. Zaheri et al. $[9,21]$ studied the facilitated transport of Eu(III) across liquid membranes (PIMs and SLMs - supported liquid membranes) using Cyanex 272 and D2EHPA as the carriers. They reported that Cyanex 272 molecules reacted with Eu(III) to form metal carrier complexes. The results can be shown as below:

$$
\mathrm{Eu}^{3+}+3(\mathrm{HA})_{2}+(\mathrm{HB})_{2} \rightarrow \mathrm{EuH}_{5} \mathrm{~A}_{6} \mathrm{~B}_{2}+3 \mathrm{H}^{+}
$$

Therefore, the use of Cyanex 272 for the transport of other REEs is justified. This work shows, for the first time, the application of polymer membrane with Cyanex 272 and Cyanex 301 for the selective recovery of $\mathrm{Ce}$ (III) and $\mathrm{La}$ (III) from the aqueous nitrate $(\mathrm{V})$ solution. A comparison of the metal ion separation process with the use of PIMs with different ion carriers was made. The transport of metal ions was characterized by the kinetic parameters, such as the rate constant $(k)$, the permeability coefficient $(P)$, and the initial flux $\left(\mathrm{J}_{\mathrm{i}}\right)$.

\section{Experimental}

\subsection{Materials}

Organic reagents, i.e., CTA, dichloromethane, 2-nitrophenyloctyl ether (NPOE), bis(2,4,4-trimethylpentyl)phosphinic acid (Cyanex 272), and bis(2,4,4-trimethylpentyl)dithiophosphinic acid (Cyanex 301) were supplied as reagent grade products by Sigma-Aldrich and used without further purification.

Inorganic chemicals, i.e., lanthanum(III) nitrate $(\mathrm{V})$ $\left(\mathrm{La}\left(\mathrm{NO}_{3}\right)_{3} \cdot 6 \mathrm{H}_{2} \mathrm{O}\right)$, cerium(III) nitrate $(\mathrm{V})\left(\mathrm{Ce}\left(\mathrm{NO}_{3}\right)_{3} \cdot 6 \mathrm{H}_{2} \mathrm{O}\right)$, and nitric acid $\left(\mathrm{HNO}_{3}\right)$ were of analytical grade and were purchased from POCh (Gliwice, Poland). Aqueous solutions were prepared with deionized water.

\subsubsection{Polymer inclusion membrane}

The membranes were prepared as described in detail elsewhere [3-6]. Solutions of CTA, the ion carrier (Cyanex 272, Cyanex 301), and the plasticizer (NPOE) in dichloromethane were prepared. A portion of this solution was poured on a flatbottom glass Petri dish which was kept on a leveled surface. Organic solvent was allowed to evaporate over a period of $12 \mathrm{~h}$.
The obtained membrane was peeled off from the Petri dish and subsequently it was washed with water and conditioned in distillated water before use.

\subsection{Methods}

Transport measurements were carried out in the experimental rig described and presented in detail elsewhere [3-6]. The volumes of source and receiving phases were both equal to $100 \mathrm{~cm}^{3}$. During experiments, membrane samples with the effective membrane area of $12.56 \mathrm{~cm}^{2}$ were used. The thickness of the membranes was measured using the digital ultrameter (MG-401, Elmetron). The values for the thickness of PIM-1 with Cyanex 272 and PIM-2 with Cyanex 301 were $72 \mu \mathrm{m}$ and $76 \mu \mathrm{m}$, respectively. The source and the receiving aqueous phases were stirred at $600 \mathrm{rpm}$, at a temperature of $22^{\circ} \mathrm{C}$. Aqueous phases were pumped through the membrane module using a multichannel peristaltic pump (PP1B-05A type, Zalimp, Poland). The permeation rate of $\mathrm{La}(\mathrm{III})$ and $\mathrm{Ce}(\mathrm{III})$ ions were determined by sampling of the source phase. Samples were subsequently analyzed using a plasma emission spectrometer MP-AES 4200 (Agilent). The source phase contained $0.01 \mathrm{M}$ $\mathrm{La}\left(\mathrm{NO}_{3}\right)_{3}$ and $0.01 \mathrm{M} \mathrm{Ce}\left(\mathrm{NO}_{3}\right)_{3}$ in distilled water. The duration of the transport process was $8 \mathrm{~h}$. The kinetics of $\mathrm{La}$ (III) and $\mathrm{Ce}$ (III) ions' transport through PIM membrane follows the kinetics of the first-order reaction - Eq. (2) [11]:

$$
\operatorname{In}\left(\frac{c}{c_{i}}\right)=-k t
$$

where $c$ is the metal ion concentration (M) in the source phase at a given time, $c_{i}$ is the initial metal ion concentration in the source phase, $k$ is the rate constant $\left(\mathrm{s}^{-1}\right)$, and $t$ is the time of transport $(s)$.

The value of rate constant $(k)$ was calculated from the plot of In (c/c) vs. time - Eq. (2). Experiments were run in duplicate and the rate-constant value is an average from the both experiments. The value of the permeability coefficient $(P)$ was subsequently calculated using Eq. (3):

$$
P=\frac{V}{A} k
$$

where $V$ is volume of the aqueous source phase and $A$ is the effective area of the membrane. The initial flux value $\left(J_{j}\right)$ was then obtained from Eq. (4), as follows:

$$
J_{i}=P \cdot c_{i}
$$

Additionally, the recovery factor (RF) was determined using Eq. (5), as follows:

$$
R F=\frac{c_{i}-c}{c_{i}} \cdot 100 \%
$$

The selectivity coefficient (S) was defined as the ratio of initial fluxes for $M_{1}$ and $M_{2}$ metal ions, respectively: 
$S=\frac{J_{i, M_{1}}}{J_{i, M_{2}}}$

\section{Results and discussion}

\subsection{Effect of ion carrier on the transport of $\mathrm{La}$ (III) and $\mathrm{Ce}$ (III)}

The aim of this study was to investigate the transport of La(III) and $\mathrm{Ce}$ (III) from nitrate solutions across PIM, depending on the kind of the ion carrier in membrane. It is well known that Cyanex 272, as well as Cyanex 301, were used as the extractants of metals in classical liquid-liquid extraction because these extractants have appropriate extracting properties of REE [17, $21,23]$. Therefore, these organophosphorus compounds were used as the ion carriers for synthesis of polymer membranes. PIM- 1 contained $20 w t \%$ of CTA, 55 wt $\%$ of NPOE, and $25 w t \%$ of Cyanex 272. The composition of PIM-2 was the following: $20 w t \%$ of CTA, 55 wt $\%$ of NPOE, and $25 w t \%$ of Cyanex 301.

In the preliminary experiments, PIM-1 with Cyanex 272 as the ion carrier was used for the transport of $\mathrm{La}$ (III) from the aqueous nitrate solution $\left([\mathrm{La}]=0.01 \mathrm{M}\right.$ ) into $1 \mathrm{M} \mathrm{H}_{2} \mathrm{SO}_{4}$. Cyanex 272 exists as a dimmer in the membrane. Metal ions are extracted by a cation-exchange mechanism. Therefore, the mechanism of reaction with REE ions can be represented as follows [22]:

$\mathrm{REE}_{a q}^{3+}+3(\mathrm{HA})_{2, \text { org }} \operatorname{REE}\left(\mathrm{HA}_{2}\right)_{3, \text { org }}+3 \mathrm{H}_{a q}{ }^{+}$

where $(H A)_{2}$ represents the dimer Cyanex 272 and REE represents the rare earth element. The subscripts aq and org denote species in the aqueous and organic phases, respectively.

In the subsequent experiments, the transport of metal ions across PIM-2 with Cyanex 301 as the ion carrier was performed. Cyanex 301 is monomeric. The mechanism of reaction with REE ions can be represented as follows [18]:

$$
\mathrm{REE}_{a q}{ }^{3+}+3 \mathrm{HA}_{\text {,org }} \mathrm{REEA}_{3, \text { org }}+3 \mathrm{H}_{a q}{ }^{+}
$$

where $H A$ represents Cyanex 301.

Figure 1 shows the kinetics dependence of $\ln \left(c / c_{i}\right)$ vs. time for the transport of $\mathrm{La}$ (III) through the studied membranes, namely PIM1 and PIM2. The linear relation of $\ln \left(c / c_{i}\right)$ vs. time shows the facilitated mechanism of $\mathrm{La}$ (III) transport through PIM with the studied compounds as the ion carriers. Similar results were observed by Kozlowska et al. [12]. They studied transport of heavy metal ions such as $\mathrm{Zn}(\mathrm{II}), \mathrm{Cd}(\mathrm{II})$, and $\mathrm{Pb}(\mathrm{II})$ using the organophosphorus acids as the carriers. They reported the diffusive mechanism of the metal ions' transport. Moreover, they found that high viscosity and low dielectric constants of the plasticizer favor the metal ions' transport across PIMs.

Figure 2 shows the RF values of La(III) vs. time transport for the experiments conducted, respectively, with the studied membranes. The highest RF of $\mathrm{La}$ (III) was $50.4 \%$ for PIM2 containing $20 \mathrm{wt} \%$ of CTA, $55 \mathrm{wt} \%$ of NPOE as the plasticizer, and $25 \mathrm{wt} \%$ of Cyanex 301 after $8 \mathrm{~h}$. This is the optimal time of the membrane processes using PIM in the studied conditions.

The subsequent studies concerned the transport of $0.01 \mathrm{M}$ $\mathrm{Ce}$ (III) from the source phase into $1 \mathrm{M}$ sulfuric acid using PIM1 and PIM-2, respectively. The kinetics of $\mathrm{Ce}(\mathrm{III})$ ion transport with the use of different ion carriers was compared (Figure 3). Figure 4 shows the relation of the RF values (\%) of $\mathrm{Ce}(\mathrm{III})$ vs. time transport across PIM1 and PIM2. As can be seen, the highest RF of $\mathrm{Ce}(\mathrm{III})$ was $63.5 \%$ after $8 \mathrm{~h}$ for PIM1 with Cyanex 272 as the ion carrier. It can be observed that the recovery of $\mathrm{Ce}$ (III) from the aqueous solution was more efficient than $\mathrm{La}(\mathrm{III})$.

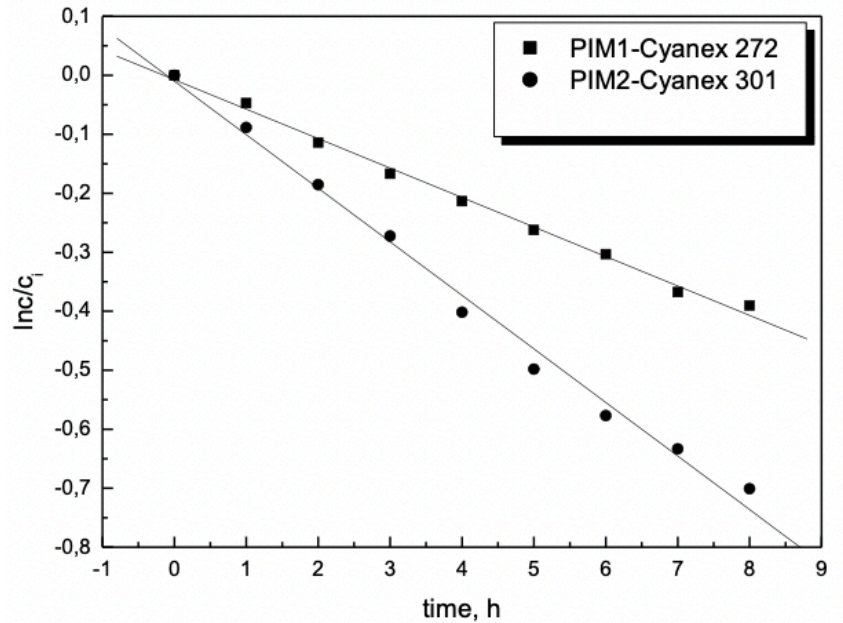

Figure 1. Relationship of $\ln \left(c / c_{i}\right)$ vs. time for $\mathrm{La}(\mathrm{III})$ transport across PIM-1 with Cyanex 272 and PIM-2 with Cyanex 301. The source phase: $0.01 \mathrm{M} \mathrm{La}(\mathrm{III})$; the receiving phase: $1 \mathrm{M} \mathrm{H}_{2} \mathrm{SO}_{4}$. PIM, polymer inclusion membrane.

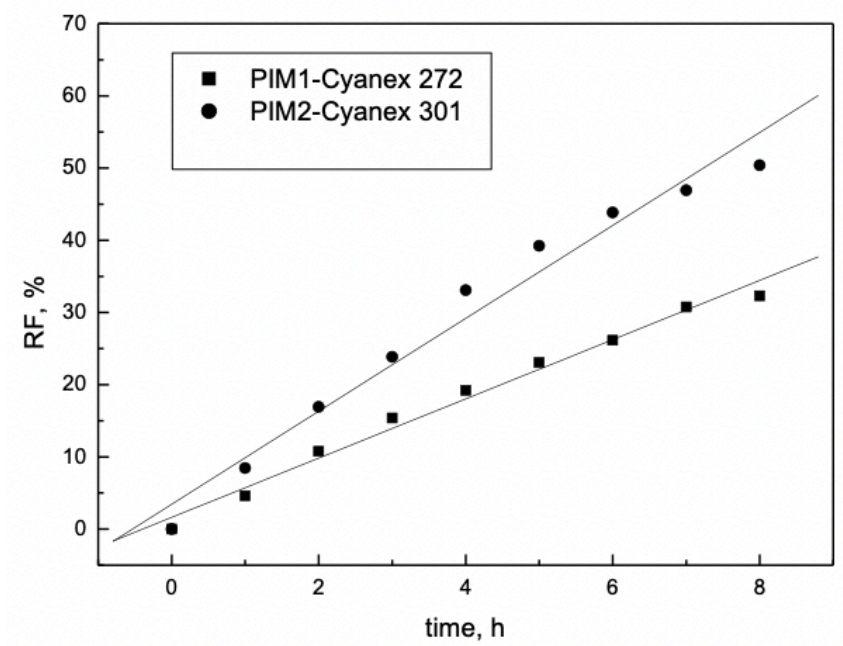

Figure 2. The RF of La(III) vs. time across PIM-1 with Cyanex 272 and PIM-2 with Cyanex 301. Conditions as in Figure 1. PIM, polymer inclusion membrane; RF, recovery factor. 


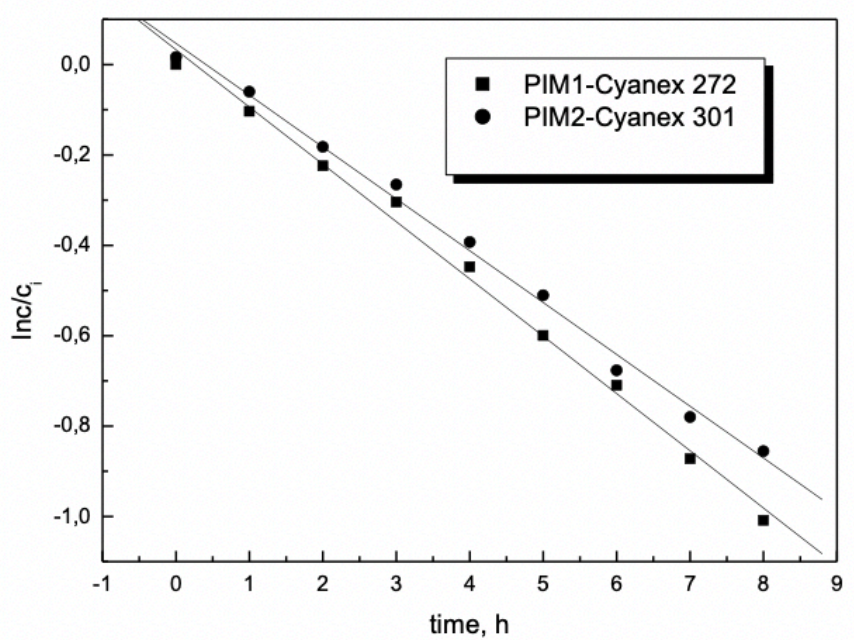

Figure 3. Relationship of $\operatorname{In}(\mathrm{c} / \mathrm{c}$ ) vs. time for Ce(III) transport across PIM1 with Cyanex 272 and PIM2 with Cyanex 301. The source phase: $0.01 \mathrm{M} \mathrm{Ce}(\mathrm{III})$; the receiving phase: $1 \mathrm{M} \mathrm{H}_{2} \mathrm{SO}_{4}$. PIM, polymer inclusion membrane.

\subsection{Selectivity studies}

The next investigations concerned the competitive transport of $\mathrm{Ce}(\mathrm{III})$ and $\mathrm{La}$ (III) from their equimolar nitrate(V) solution using PIM1 and PIM2. Table 1 shows the kinetic parameters of the transport process (the rate constant $(\mathrm{k})$ and the initial flux $\left(\mathrm{J}_{\mathrm{i}}\right)$, as well as the selectivity order). The relatively low values of the initial fluxes are probably due to the high stability of metal-ion carrier complexes [28]. As can be observed, the initial fluxes for $\mathrm{Ce}(\mathrm{III})$ are much higher than La(III) across PIM1 with Cyanex 272, as well as PIM2 with Cyanex 301 . The selectivity of this extraction process of $\mathrm{Ce}(\mathrm{III})$ towards $\mathrm{La}(\mathrm{III})$ is significantly higher for the membrane with Cyanex 272 as the carrier. Therefore, Cyanex 272 can be recommended as the effective and selective ion carrier for the preparation of PIM in order to separate $\mathrm{Ce}(\mathrm{III})$ and $\mathrm{La}(\mathrm{III})$.

As can be seen from Table 1, the highest RF was obtained for $\mathrm{Ce}(\mathrm{III})$ across PIM1 (62.3\%). The highest selectivity coefficient for Ce(III) over La(III) was 2.4 for this membrane. This value is twice higher compared to the transport across PIM2 containing Cyanex 301. It is noteworthy to mention that the physicochemical properties of organophosphorus acids included as the ion carriers in the membranes are varied. Table 2 shows the selected parameters describing the properties of Cyanex 272 and Cyanex 301 [29]. As can be surmised, the difference in

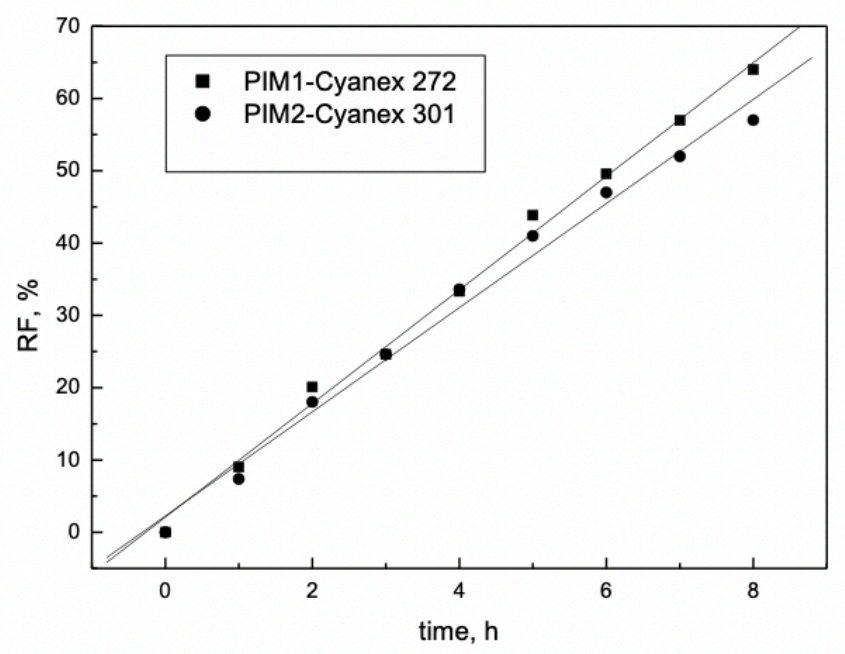

Figure 4. The RF of $\mathrm{Ce}(\mathrm{III})$ vs. time across PIM-1 with Cyanex 272 and PIM-2 with Cyanex 301. Conditions as in Figure 3. PIM, polymer inclusion membrane; RF, recovery factor.

the transport abilities of metal ions between Cyanex 272 and Cyanex 301 might be due to their viscosity and $\mathrm{pK}_{\mathrm{a}}$ values. The order of decreasing $\mathrm{pK}_{\mathrm{a}}$ of the used organophosphorus acids is the following: Cyanex272 > Cyanex 301 [29].

Also, the high value of Cyanex 301 viscosity influences the transport properties of polymer membrane. Therefore, the influence of the various factors on the transport of metal ions

Table 2. Physicochemical properties of Cyanex 272 and Cyanex 301 [29]

\begin{tabular}{|c|c|c|}
\hline Parameter & Cyanex 272 & Cyanex 301 \\
\hline Density & $\begin{array}{c}0.916 \mathrm{~g} / \mathrm{cm}^{3} \text { at } \\
20^{\circ} \mathrm{C}\end{array}$ & $\begin{array}{c}0.950 \mathrm{~g} / \mathrm{cm}^{3} \text { at } \\
20^{\circ} \mathrm{C}\end{array}$ \\
\hline Viscosity & $14.2 \mathrm{cP}$ at $25^{\circ} \mathrm{C}$ & $78 \mathrm{cP}$ at $24^{\circ} \mathrm{C}$ \\
\hline $\mathrm{pK}_{\mathrm{a}}$ & 6.37 & 2.61 \\
\hline Boiling point & $>300^{\circ} \mathrm{C}$ & $\begin{array}{c}\text { Decomposes at } \\
220^{\circ} \mathrm{C}\end{array}$ \\
\hline $\begin{array}{c}\text { Pour point } \\
\text { Ignition } \\
\text { temperature }\end{array}$ & $-32^{\circ} \mathrm{C}$ & $-34^{\circ} \mathrm{C}$ \\
\hline
\end{tabular}

Table 1. Kinetic parameters for competitive transport of $\mathrm{Ce}$ (III) and La(III); the source phase: $0.01 \mathrm{M} \mathrm{Ce}(\mathrm{III}), 0.01 \mathrm{M}$ La(III); the receiving phase: $1 \mathrm{M} \mathrm{H}_{2} \mathrm{SO}_{4}$

\begin{tabular}{|c|c|c|c|c|c|}
\hline Membrane & Metal ions & $\begin{array}{l}\text { Rate constant, } \\
\qquad \mathbf{k}, \mathbf{h}^{-1}\end{array}$ & $\begin{array}{l}\text { Initial flux, } J_{i,} \\
\text { mmol } \mathrm{m}^{-2} \mathbf{s}^{-1}\end{array}$ & RF after 8 h, \% & Selectivity order \\
\hline \multirow[t]{2}{*}{ PIM with Cyanex 272} & $\mathrm{La}(\mathrm{III})$ & 0.048 & 10.7 & 31.4 & $\begin{array}{c}\mathrm{Ce}(\mathrm{III})>\mathrm{La}(\mathrm{III}) \\
2.4\end{array}$ \\
\hline & $\mathrm{Ce}(\mathrm{III})$ & 0.116 & 25.7 & 62.3 & \\
\hline \multirow[t]{2}{*}{ PIM with Cyanex 301} & $\mathrm{La}(\mathrm{III})$ & 0.088 & 19.5 & 58.2 & $\begin{array}{c}\mathrm{Ce}(\mathrm{III})>\mathrm{La}(\mathrm{III}) \\
1.2\end{array}$ \\
\hline & $\mathrm{Ce}(\mathrm{III})$ & 0.104 & 23.1 & 50.4 & \\
\hline
\end{tabular}

PIM, polymer inclusion membrane; RF, recovery factor. 
Table 3. Composition of PIMs containing various amounts of plasticizer NPOE and carrier Cyanex 272

\begin{tabular}{|c|c|c|c|c|}
\hline No. & Polymer support & Plasticizer & Ion carrier & PIM thickness, $\mu$ m \\
\hline & CTA, wt. $\%$ & NPOE, wt. $\%$ & Cyanex 272, wt. \% & 65 \\
\hline PIM1 & 21 & 45 & 34 & 72 \\
\hline PIM2 & 20 & 55 & 25 & 78 \\
\hline PIM3 & 22 & 61 & 17 & 78 \\
\hline
\end{tabular}

CTA, Cellulose triacetate; PIM, polymer inclusion membrane.

Table 4. Kinetic parameters for competitive transport of $\mathrm{Ce}(\mathrm{III})$ and $\mathrm{La}(\mathrm{III})$ for PIM containing various amounts of plasticizer NPOE and carrier Cyanex 272. The source phase: $0.01 \mathrm{M} \mathrm{Ce}(\mathrm{III}), 0.01 \mathrm{M} \mathrm{La}(\mathrm{III})$; the receiving phase: $1 \mathrm{M} \mathrm{H}_{2} \mathrm{SO}_{4}$

\begin{tabular}{|c|c|c|c|c|c|}
\hline Membrane & Metal ions & $\begin{array}{l}\text { Rate constant, } \\
\qquad k, h^{-1}\end{array}$ & 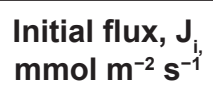 & RF after 8 h, \% & Selectivity order \\
\hline \multirow[t]{2}{*}{ PIM1 } & $\mathrm{La}(\mathrm{III})$ & 0.047 & 10.4 & 30.8 & $\begin{array}{c}\mathrm{Ce}(\mathrm{III})>\mathrm{La}(\mathrm{III}) \\
2.2\end{array}$ \\
\hline & $\mathrm{Ce}(\mathrm{III})$ & 0.104 & 23.0 & 57.4 & \\
\hline \multirow[t]{2}{*}{ PIM2 } & $\mathrm{La}(\mathrm{III})$ & 0.048 & 10.7 & 31.5 & $\begin{array}{c}\mathrm{Ce}(\mathrm{III})>\mathrm{La}(\mathrm{III}) \\
2.4\end{array}$ \\
\hline & $\mathrm{Ce}(\mathrm{III})$ & 0.116 & 25.7 & 62.3 & \\
\hline \multirow[t]{2}{*}{ PIM3 } & $\mathrm{La}(\mathrm{III})$ & 0.044 & 9.7 & 27.7 & $\begin{array}{c}\mathrm{Ce}(\mathrm{III})>\mathrm{La}(\mathrm{III}) \\
2.1\end{array}$ \\
\hline & $\mathrm{Ce}(\mathrm{III})$ & 0.094 & 20.8 & 53.2 & \\
\hline
\end{tabular}

PIM, polymer inclusion membrane; RF, recovery factor.

from the aqueous solutions should be taken into consideration. Bhattacharyya et al. [18] also used Cyanex 301 as the carrier of lanthanides $\mathrm{Ln}$ (i.e., $\mathrm{Ln}^{3+}, \mathrm{Eu}^{3+}, \mathrm{Tb}^{3+}, \mathrm{Ho}^{3+}, \mathrm{Yb}^{3+}$ and $\mathrm{Lu}^{3+}$ ) in hollow-fiber SLM. Their studies indicated that mechanism of the complexation of trivalent lanthanides using Cyanex 301 from aqueous nitrate medium is the following:

$\mathrm{Ln}^{3+}+2 \mathrm{HA}_{(\mathrm{o})}+\mathrm{NO}_{3}^{-} \Leftrightarrow \mathrm{Ln}(\mathrm{A})_{2}\left(\mathrm{NO}_{3}\right)_{(\mathrm{o})}+2 \mathrm{H}^{+}$

In turn, Zaheri et al. [9] applied the mixture of Cyanex 272 and D2EHPA as the ion carrier for the transport of Eu(III) across PIM from nitrate media and reported that transport of metal ions was membrane-diffusion-limited.

\subsection{The effect of PIM composition on the transport of Ce(III) and La(III)}

Next, the effect of Cyanex 272 and NPOE contents in the membrane on the transport and separation of $\mathrm{Ce}(\mathrm{III})$ and $\mathrm{La}$ (III) was studied. Table 3 shows the composition of PIMs containing various amounts of the ion carrier and the plasticizer at constant concentrations of CTA. These membranes were used for the selective removal of metal ions from their equimolar nitrate $(\mathrm{V})$ solution. Table 4 presents the kinetic parameters for the transport of $\mathrm{Ce}$ (III) and $\mathrm{La}(\mathrm{III})$ for PIMs of different composition. As can be observed, the initial flux is low at high content of the plasticizer (PIM-3) because thickness of membranes increases with increasing content of NPOE (Table 3). Regel-Rosocka et al. [1] observed that increasing thickness affects transport resistance and may cause decrease in the initial flux. On the other hand, the initial flux is low when the content of the ion carrier (PIM-1) is high, because the viscosity of the membranephase increases with increasing amount of this component [30]. Therefore, PIM-2 containing 20 wt $\%$ of CTA, 55 wt $\%$ of NPOE, and 25 wt $\%$ of Cyanex 272 was chosen as the membrane with the optimal composition in the studied conditions.

\section{Conclusions}

The transport of $\mathrm{Ce}(\mathrm{III})$ and $\mathrm{La}(\mathrm{III})$ through PIM containing Cyanex 272 and Cyanex 301 as the ion carriers was investigated. The obtained results showed that transport rate of the studied metal ions strongly depended on the type of the ion carrier in the polymer membrane. The highest initial flux of $\mathrm{Ce}$ (III) ions was observed for PIM with Cyanex 272. On the other hand, the best effect of $\mathrm{La}$ (III) transport was noticed for PIM with Cyanex 301. Nevertheless, the highest selectivity coefficient of $\mathrm{Ce}$ (III) towards $\mathrm{La}$ (III) $\left(\mathrm{S}_{\mathrm{Ce} / \mathrm{La}}\right.$ ) in the competitive transport from the equimolar solution was obtained for PIM containing $20 \mathrm{wt} \%$ of CTA, 55 wt $\%$ of NPOE, and $25 \mathrm{wt} \%$ of Cyanex 272. This membrane was successfully used for the selective transport of $\mathrm{Ce}(\mathrm{III})$ over $\mathrm{La}$ (III) ions from the nitrate aqueous solution. The results confirmed that the composition of PIMs (especially the content of the plasticizer and the ion carrier) has a significant influence on the kinetic parameters of the transport and the separation of $\mathrm{Ce}(\mathrm{III}) / \mathrm{La}(\mathrm{III})$. 


\section{References}

[1] Regel-Rosocka, M., Nowak, L., Wisniewski, M. (2012). Removal of Zn(II) and iron ions from chloride solutions with phosphonium ionic liquids. Separation and Purification Technology, 97, 158-163.

[2] Baczynska, M., Rzelewska M., Regel-Rosocka, M., Wisniewski, M. (2016). Transport of iron ions from chloride solutions using cellulose triacetate matrix inclusion membranes with an ionic liquid carrier. Chemical Papers, 70(2), 172-179.

[3] Makowka, A., Pospiech, B. (2019). Synthesis of polymer inclusion membranes based on cellulose triacetate for recovery of lanthanum(III) from aqueous solutions. Autex Research Journal, 19(3), 288-292.

[4] Pospiech, B. (2015). Studies on extraction and permeation of cadmium(II) using Cyphos IL 104 as selective extractant and ion carrier. Hydrometallurgy, 154, 88-94.

[5] Pospiech, B. (2015). Application of phosphonium ionic liquids as ion carriers in polymer inclusion membranes (PIMs) for separation of cadmium(II) and copper(II) from aqueous solutions. Journal of Solution Chemistry, 44, 2431-2447.

[6] Pospiech, B. (2018). Facilitated transport of palladium(II) across polymer inclusion membranes with ammonium ionic liquid as effective carrier. Chemical Papers, 72, 301 308.

[7] Ansari, A. S., Mahopatra, P. K., Manchandra, V. K. (2010). Cation transport across plasticized membranes containing $N, N, N$ ',N'-tetraoctyl-3-oxapentanediamide (TODGA) as the carrier. Desalination, 262, 196-201.

[8] Kusumocahyo, S. P., Kanamori, T., Sumaru, K., Aomatsu, S., Matsuyama, H., et al. (2004). Development of polymer inclusion membranes based on cellulose triacetate: Carrier-mediated transport of cerium(III). Journal of Membrane Science, 244, 251-257.

[9] Zaheri, P., Ghassabzadeh, H. (2017). Preparation of polymer inclusion membrane including mixture of D2EHPA and Cyanex 272 for the extraction of Eu from nitrate media. Chemical Papers, 71, 1623-1631.

[10] Wang, D., Hu, J., Liu, D., Chen, Q., Li, J. (2017). Selective transport and simultaneous separation of $\mathrm{Cu}(\mathrm{II}), \mathrm{Zn}(\mathrm{II})$ and Mg(II) using a dual polymer inclusion membrane system. Journal of Membrane Science, 524, 205-213.

[11] Danesi, P. R. (1984). Separation of metal species by supported liquid membranes. Separation and Purification Technology, 19, 857-894.

[12] Kozlowska, J., Kozlowski, C. A., Walkowiak, W. (2007). Transport of $\mathrm{Zn}(\mathrm{II}), \mathrm{Cd}(\mathrm{II})$, and $\mathrm{Pb}(\mathrm{II})$ across CTA plasticized membranes containing organophosphorous acids as ion carriers. Separation and Purification Technology, 57, 430434.

[13] Lister, T. E., Wang, P., Anderko, A. (2014). Recovery of critical and value metals from mobile electronics enabled by electrochemical processing. Hydrometallurgy, 149, 228237.

[14] Jha, M. K., Kumari A., Pand, R., Kumar, J. R., Yoo, K., et al. (2016). Review on hydrometallurgical recovery of rare earth metals. Hydrometallurgy, 165, 2-26.

[15] Xie, F., Zhang, T. A., Dreisinger, D., Doyle, F. (2014). A critical review on solvent extraction of rare earths from aqueous solutions. Minerals Engineering, 56, 10-28.
[16] Zhao, Z., Qiu, Z., Yang, J., Lu, S., Cao, L., et al. (2017). Recovery of rare earth elements from spent fluid catalytic cracking catalysts using leaching and solvent extraction techniques. Hydrometallurgy, 167, 183-188.

[17] Abhilash Sinha, S., Sinha, M. K., Pandey, B. D. (2014). Extraction of lanthanum and cerium from Indian red mud. International, Journal of Mineral Processing, 127, 70-73.

[18] Bhattacharyya, A., Mohapatra, P. K., Ansari, S. A., Raut, D. R., Manchanda, V. K. (2008). Separation of trivalent actinides from lanthanides using hollow fiber supported liquid membrane containing Cyanex 301 as the carrier. Journal of Membrane Science, 312, 1-5.

[19] Mishra, S., Sahu, S. K. (2016). Solvent extraction of Ce(III) from nitric acid medium using binary mixture of $P C 88 \mathrm{~A}$ and Cyanex 921. Hydrometallurgy, 166, 252-259.

[20] Abdeltawab, A., Nii, S., Kawaizumi, F., Takahashi, K. (2002). Separation of La and Ce with PC-88A by countercurrent mixer-settler extraction column. Separation and Purification Technology, 26, 265-272.

[21] Zaheri, P., Ghassabzadeh, H., Abolghasemi, H., Maraghe, M. G., Mohammadi, T. (2017). Facilitated transport of europium through supported liquid membrane Rusing 272 as Cartier and mass transfer modeling. The Canadian Journal of Chemical Engineering, 95, 524-534.

[22] Swain, B., Otu, E. O. (2011). Competitive extraction of lanthanides by solvent extraction using Cyanex 272: Analysis, classification and mechanism. Separation and Purification Technology, 83, 82-90.

[23] Saleh, M. I., Bari, M. F., Saad, B. (2002). Solvent extraction of lanthanum(III) from acidic nitrate-acetato medium by Cyanex 272 in toluene. Hydrometallurgy, 63, 75-84.

[24] Belova, V. V., Voshkin, A. A., Kholkin, A. I., Paytram, A. K. (2009). Solvent extraction of some lanthanides from chloride and nitrate solutions by binary extractants. Hydrometallurgy, 97, 198-204.

[25] Banda, R.; Jeon, H.; Lee, M. (2012). Solvent extraction separation of $\mathrm{Pr}$ and $\mathrm{Nd}$ from solution containing $\mathrm{La}$ using Cyanex 272 and its mixture with other extractants. Separation and Purification Technology, 98, 481-487.

[26] El-Nadi (2012). Lanthanum and neodymium from Egyptian monazite: Synergistic extractive separation using organophosphorus reagents. Hydrometallurgy, 119-120, 23-29.

[27] Kuang, S., Zhang, Z., Li, Y., Wei, H., Liao, W. (2017). Synergistic extraction and separation of rare earths from chloride medium by the mixture of HEHAPP and D2EHPA. Hydrometallurgy, 174, 78-83.

[28] Nguyen, V. N., Nguyen, T. H., Lee, M. S. (2020). Review on the comparison of the chemical reactivity of Cyanex 272, Cyanex 301 and Cyanex 302 for their application to metal separation from acid media. Metals, 10, 1105-1119.

[29] Ayanda, O. S., Adekola, F. A., Baba A. A., Ximba, B. J., Fatoki, O. S. (2013). Application of Cyanex巴 extractant in cobalt/nickel separation process by solvent extraction. International Journal of Physical Sciences, 8(3), 89-97.

[30] Kaya, A., Onac, C., Surucu, A., Karapinar, E., Alpoguz, H. K., Tabakci, B. (2014). Preparation of CTA-based polymer inclusion membranes using calyx[4]arene derivative as a carrier for Cr(VI) transport. Journal of Inclusion Phenomena and Macrocyclic Chemistry, 79, 103-111. 